\title{
PNGVL4a-CRT/E7(detox) DNA Vaccine
}

\author{
National Cancer Institute
}

\section{Source}

National Cancer Institute. pNGVL4a-CRT/E7(detox) DNA Vaccine. NCI Thesaurus. Code C88289.

A cancer vaccine consisting of the DNA plasmid pNGVL4a-A encoding calreticulin (CRT) linked to a detox form of human papillomavirus (HPV) type 16 E7 antigen, with potential immunomodulating and antineoplastic activities. Upon administration, this vaccine may generate a potent cytotoxic T-lymphocyte $(C T L)$ response against E7-expressing tumor cells, resulting in tumor cell death. For E7(detox), the amino acids in E7 at positions 24 (cysteine to glycine) and 26 (glutamic acid to glycine) were substituted. CRT, a $46 \mathrm{kDa}$ protein located in the lumen of the cell's endoplasmic reticulum (ER), may potentiate MHC class I presentation of HPV-16 E7 to E7-specific CD8-positive T cells. In addition, pNGVL4a-A contains two short immunostimulatory DNA sequences (ISS) in the noncoding region, which may elicit the production of IFN- and IL-12 in transfected keratinocytes and dermal antigen presenting cells (APCS), resulting in a potent T helper cell type 1 response. 